\title{
Combined effects of landscape composition and pesticide use on herbivore and pollinator functions in smallholder farms
}

Quentin Struelens ${ }^{1,2^{*}}$ (D), Diego Mina ${ }^{3}$ and Olivier Dangles ${ }^{2,3}$

\begin{abstract}
Background: Landscape composition has the potential to foster regulating ecosystem services such as pollination and biocontrol in temperate regions. However, most landscape studies do not take pesticide use into account even though it is the main control strategy worldwide and has negative impacts on beneficial insects. Moreover, few studies have explored these combined effects in smallholder cropping system with diverse landscapes and small cultivated fields.
\end{abstract}

Methods: We assessed the effect of semi-natural cover and pesticide use on pollinator and herbivore abundances and functions in 9 fields in the Ecuadorian Andes through participatory experiments with smallholder farmers. We performed a path analysis to quantify the effects of landscape and pesticide use on herbivory, pollination and ultimately yield.

Results: Pesticide use significantly reduced pollinator abundance but had no significant effect on pest abundance. Similarly, we found non-significant effects of landscape composition on either herbivory and pollination. The study also provides new information on understudied Andean lupine's pests and pollinators, whose application for small farmers is discussed. Finally, we hypothesize that peculiarities of tropical smallholder cropping systems and landscapes could explain the non-significant landscape effects on insect-based processes, which calls for more research in places outside the well-studied temperate region.

Conclusions: Landscape composition did not show any significant effect on pest and pollinator while pesticide use decreased the abundance pollinators, but with no significant effect on yield. This study also provides information about Andean lupine reproduction and overcompensation mechanisms that could be of interest for local farmers and researchers of this understudied crop.

Keywords: Andean lupine, Biological control, Ecosystem services, Exclusion experiment, Insecticide use, Participatory research

\section{Introduction}

Smallholder farmers in developing countries are heavily dependent on insecticides for herbivorous pest control (Schreinemachers and Tipraqsa 2012). Most of

*Correspondence: quentin.struelens@gmail.com

1 Muséum National d'Histoire Naturelle, Sorbonne Universités, 57 rue Cuvier, 75005 Paris, France

Full list of author information is available at the end of the article these insecticides have a broad spectrum of action (e.g. organophosphates, carbamates) and can therefore harm non-target organisms (Gill and Garg 2014). Even sublethal doses have detrimental effects such as disturbing foraging behaviour and memory abilities, reducing longevity and immunity (Desneux et al. 2007; Blacquière et al. 2012; Gill et al. 2012). Among the non-target insects, some are beneficial for crop production, such as natural enemies and pollinators. When natural enemies

c) The Author(s) 2021. This article is licensed under a Creative Commons Attribution 4.0 International License, which permits use, sharing, adaptation, distribution and reproduction in any medium or format, as long as you give appropriate credit to the original author(s) and the source, provide a link to the Creative Commons licence, and indicate if changes were made. The images or other third party material in this article are included in the article's Creative Commons licence, unless indicated otherwise in a credit line to the material. If material is not included in the article's Creative Commons licence and your intended use is not permitted by statutory regulation or exceeds the permitted use, you will need to obtain permission directly from the copyright holder. To view a copy of this licence, visit http://creativeco mmons.org/licenses/by/4.0/. The Creative Commons Public Domain Dedication waiver (http://creativecommons.org/publicdomain/ zero/1.0/) applies to the data made available in this article, unless otherwise stated in a credit line to the data. 
(predators, parasitoids or entomopathogens) are killed by pesticides but a moderate number of pests survive, pest outbreaks may occur due to a decrease in biological pest control (Dutcher 2007). When pollinators are killed by pesticides, it reduces the pollination service for the crop and triggers a reduction in yield, if the crop is dependent on animal-mediated pollination. Therefore, pesticide use against a phytophagous insect can lead to undesired adverse consequences on both biocontrol and pollination.

Increasing the natural habitats surrounding crop fields has been proposed as an alternative solution to herbivore control while mitigating the negative impacts of pesticides (Landis et al. 2000; Bianchi et al. 2006). With a higher diversity of natural and cropped areas in the landscape, natural enemies are more likely to find suitable resources (host plant, nectar...) when compared to monocultures (Gurr et al. 2017). Natural habitats also provide resources for pollinators, thereby enhancing in-field pollination and potentially crop production (Ricketts et al. 2008). Overall, increasing natural habitat in landscape surrounding the fields has been correlated in many cases with higher biocontrol and pollination services (Shackelford et al. 2013), even though few data exist from tropical regions (Poveda et al. 2012; Haan et al. 2020).

However, the majority of research studying the effect of surrounding landscape on agricultural ecosystem services (ES), such as pollination or biocontrol, have been carried out in fields where no pesticide was sprayed (see review in Veres et al. 2013), which may not be realistic. Indeed, both mechanisms (pesticide use and landscape provision of ecosystem services) occur and interact together, as it is the case in smallholder cropping systems. Therefore most of these agricultural landscapes encompass a mosaic of sprayed and unsprayed areas, combined with (semi-)natural and cropped areas. Recent studies have thus focused on understanding how the interaction between landscape and pesticide use impacts biological control (Ricci et al. 2009, 2019; Gagic et al. 2017, 2019). Nevertheless, few studies have included pollination in the analysis, even though it is also impacted by both landscape and pesticide use (but see Samnegård et al. 2016) and to our knowledge none in a tropical setting.

Thus, there is a need to understand how landscape composition and pesticide interact and affect pollination, herbivory and ultimately yield. We chose to focus on the two lower levels of the biocontrol tritrophic interactions (natural enemy-herbivore-yield) because the effect of landscape on natural enemies does not necessarily translate into an effect on herbivory or yield (Chaplin-Kramer et al. 2011). Moreover, yield is rarely considered in landscape-based biocontrol studies (Veres et al. 2013; in 14\% of the responses included in the review by Karp et al. 2018), yet, this is an important metric for farmers. We therefore established a conceptual framework detailling the potential effect of landscape structure and pesticide use on yield, through their combined effects on herbivores and pollinators (Fig. 1). This framework relies on two main hypotheses. On the one hand, we reasoned that a more diverse surrounding landscape would result in a higher yield, through an increase in pollination and a decrease in herbivory. On the other hand, we predicted a more balanced effect of pesticide use on yield, through a decrease in both pollination and herbivory (Fig. 1). In this study, we tested these hypotheses using lupine grown in the tropical Andes as a study model. Our specific objectives were (i) to assess the combined effect of landscape and pesticide on both pollination and herbivory, (ii) to measure both the abundances and functions of pollinators and herbivores, and (iii) to quantify the effect on yield. Smallholder agricultural landscapes are relevant and realistic models because they incorporate small fields with surrounding semi-natural habitats and a diversity of pesticide management strategies.

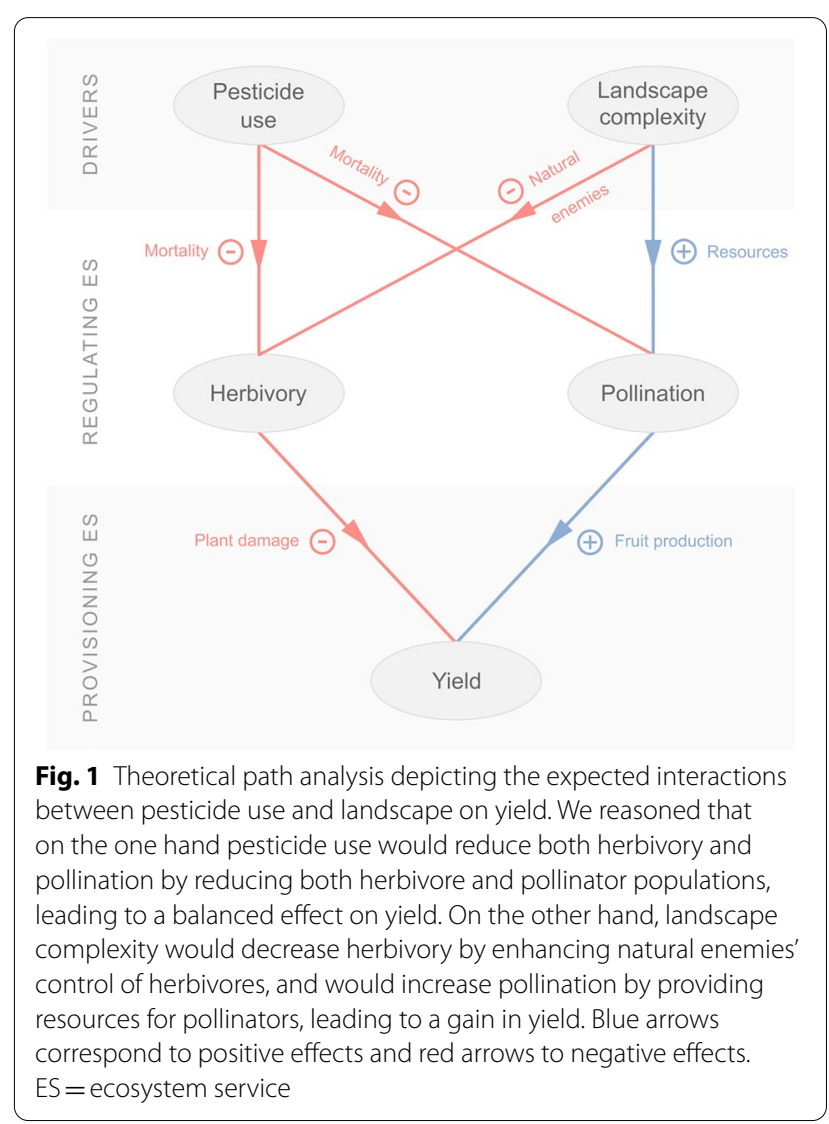




\section{Materials and methods \\ Study crop}

This study focuses on the Andean lupine (Lupinus mutabilis Sweet), a legume crop cultivated in the tropical Andes for its edible beans rich in proteins. This crop was once extensively cultivated by pre-Incan civilizations, then became supplanted mostly by fava beans during the Spanish colonization (Cowling et al. 1998). However, in the early 2000's the Ecuadorian government promoted its cultivation, leading to a renewed interest by farmers and consumers (Nicklin et al. 2006). In this context, Andean lupine crops are now found over a gradient of agricultural intensification, reflected in the surrounding landscape complexity and crop management. The expansion of Andean lupine cultivation in Ecuador went along with an increase in predation by herbivore invertebrates (Caicedo and Peralta 2000). Among these herbivores, the apex fly borer (Anthomyiidae, see below for taxonomic details) is ubiquitous in lupine crops and attacks the plant throughout its whole lifecycle (Mina et al. 2017). Pesticide application is the main option available for Ecuadorian farmers to control pest populations. Therefore, Andean lupine is a suitable crop to study the combined effect of pesticide use and landscape complexity in tropical latitudes, as it grows along a gradient of landscape complexity and pesticide use.

\section{Study sites}

The study was carried on within 30 fields owned by local farmers between January and October 2017. Field selection was a compromise between the need to include different communities with different practices and landscape compositions, and farmers' willingness to participate to the study. We only selected fields sown with "Andino 450" variety of Andean lupine. To obtain the estimates of ecosystem (dis)services (pollination and herbivory) and crop management (pesticide use), we combined experimental and observational approaches with farmer surveys. The number of pesticide applications during the crop lifecycle was determined through interviews with the farmers. A diversity of pesticides was mentioned by the farmers: Acephate, Carbosulfan, Cartap, Deltamethrin and Chlorfenapyr.

\section{Landscape-scale analysis}

Orthophotos of the landscape surrounding each field were obtained by flying a drone (DJI Phantom Pro 4, 20 Mpx camera 4:3 ratio, $4864 \times 3648$ px resolution, RGB channels; Fig. 2a). We used Pix4Dcapture software at $200 \mathrm{~m}$ altitude with $60 \%$ overlap between shots, covering a circle of $400 \mathrm{~m}$ radius around the field (50 ha). In landscapes with large differences in altitude we flew the drone at $300 \mathrm{~m}$ to avoid any image distortion. An ortho-mosaic image was generated by Pix4D software that combined 81 shots for each field (see Faye et al. 2016). We downscaled the images to a $40 \mathrm{~cm} /$ pixel resolution. Fields were selected at least $1 \mathrm{~km}$ away from each other to avoid any overlap between surrounding landscapes.

To determine land use cover we defined a classification scheme (Additional file 1: Table S1) with 15 classes based on the knowledge of the study areas and local crop rotations. Land use was determined by visual inspection of the orthophotos. We used Random Forest algorithm (ntree $=500$ ) to classify the pixels based on RGB channels (Hayes et al. 2014). We manually drew a set of polygons for each land use on every image (ranging from 67 to 122 polygons per image; Additional file 1: Table S2). These polygons were randomly separated into a calibration dataset $(70 \%)$ used to calibrate the classification model and an evaluation dataset (30\%) to evaluate the model classification ability (Additional file 1: Table S3). We decided to use the fallow and grassland classes as a proxy of the semi-natural cover because this is where most of the non-crop flowering plants are naturally growing. Indeed, in the Andean inter-valleys, the tree rows surrounding the crops are mainly composed of eucalyptus and pines where few flowers grow (pers. obs). The area of semi-natural cover in the surrounding landscape of the 11 study fields ranged from $20 \%$ of up to $67 \%$ (Additional file 1: Table S4).

\section{Monitoring of insect populations}

Within each lupine field, the abundance of pollinators and herbivores was estimated using three pitfall and three colour traps. We chose a participatory monitoring approach, meaning that the setup and gathering of the traps were carried out by the farmers themselves (and their relatives) after being thoroughly trained (Fig. $2 \mathrm{~b}$ ). The colour trap consisted of a yellow bowl $(40 \mathrm{~cm}$ in diameter and $20 \mathrm{~cm}$ deep) and the pitfall trap of a plastic cup $(8 \mathrm{~cm}$ in diameter and $15 \mathrm{~cm}$ deep) filled with water and a few drops of soap. All the trapped insects were preserved in $70 \%$ ethanol from collection to identification in the lab. The traps were set up in the fields from March to July 2017, and the time between set-up and collection varied between 6 and 64 days (mean $=24$ days) due to variations in farmers' availability. To account for this uneven sampling, we divided the observed abundances by the number of days corresponding to the trapping time. Then, the mean abundance of pollinators and apex borers were averaged across traps. Lupine apex borer fly abundance was considered as a good estimate of herbivore abundance because (i) it is a widespread herbivorous insect of concern for farmers, (ii) it feeds throughout the whole crop cycle, and (iii) its damage is easily visible through plant architecture changes. In order 

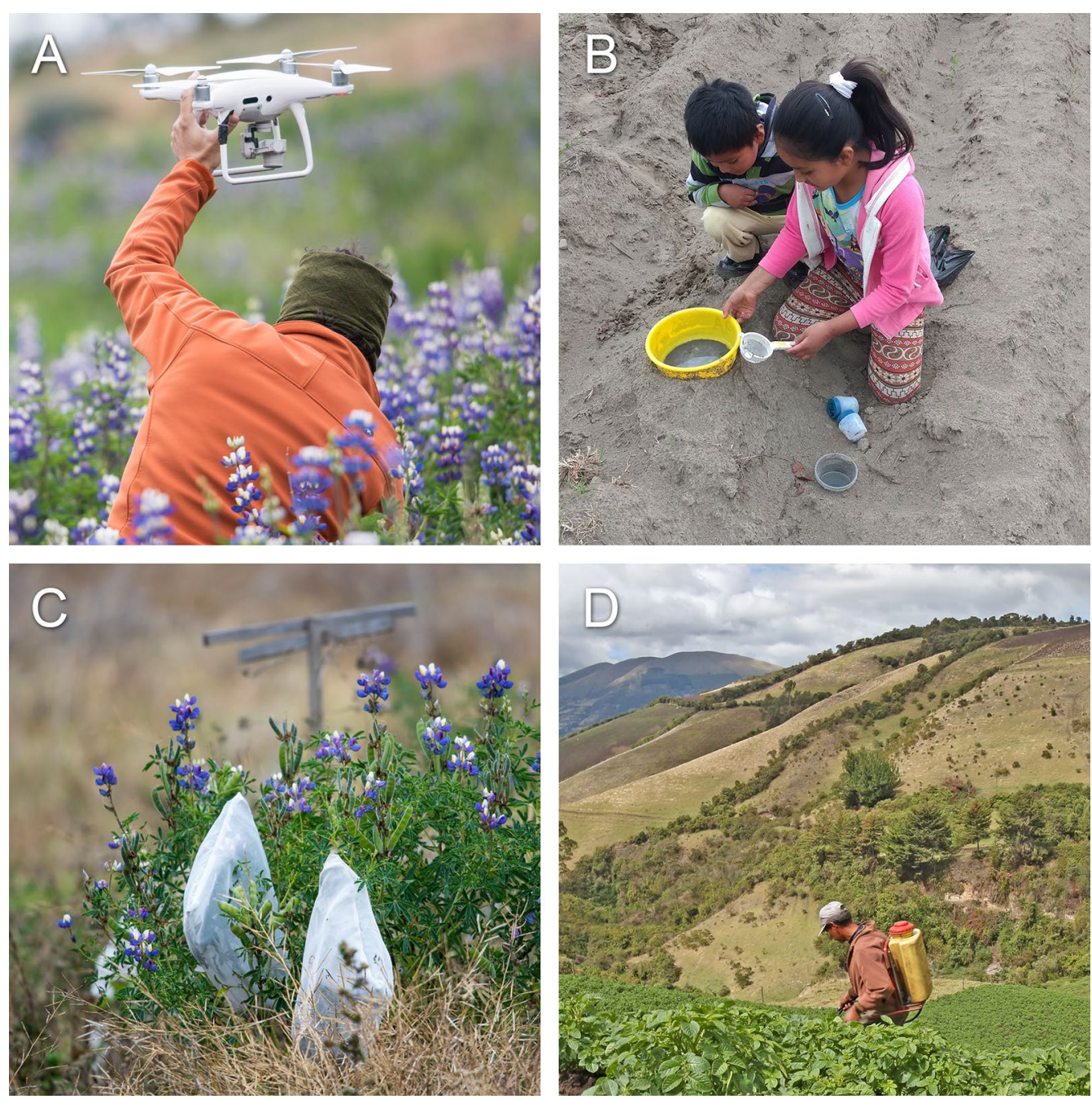

Fig. 2 Pictures showing the diversity of methods used in this study. a Drone acquisition of landscape images. b Participatory monitoring of insects with local farmers. $\mathbf{c}$ Insect exclusion experiments $\mathbf{d}$ Farmer spraying pesticides and Andean landscape in the background

to determine the taxonomic status of the lupine apex borer fly, we extracted DNA from on specimen and performed a DNA barcoding on COI gene following widely used protocols (Morgulis et al. 2008). We identified the morphospecies as being a member of the Anthomyiidae family, potentially from the genus Lasiomma. We characterized pollinators by taking into account all hymenopterans belonging to the Apidae family as it is the only group for which the pollination role was ascertained (Roubik 1995; Ochoa-Zavala et al. 2016). We could not include natural enemies within our framework because of the lack of knowledge about the lupine apex borer's natural enemies. Overall, entomofauna in the Andean intervalley is largely unknown and has not been described (e.g. Mina et al. 2017), which makes insect identification difficult. Compared to extensive and long-term research in the Amazonian region (e.g. since Bates 1862), it is surprising to witness that most of the less-diverse entomofauna in the Andes remains largely unknown.

\section{Exclusion experiments}

We used in situ exclusion experiments to estimate herbivory and pollination in the focal crop within the landscape (Fig. 2c). Exclusion experiments allow to compare the sole effect of herbivory or pollination in fields scattered across a large geographical range, neutralizing the differences in abiotic conditions between fields (climate, topography, soil texture, etc.; Chaplin-Kramer et al. 2011). To estimate herbivory, three cages were installed around randomly selected lupine plants in each field to exclude all herbivores from germination to flowering. Several seeds per hole are traditionally sown, and the density of plants varied across cages depending on the farmer's practice. Cages consisted in a wooden frame of 
$1 \mathrm{~m}$ high, a top cross of $0.5 \times 0.5 \mathrm{~m}$, wrapped with a $0.36 \mathrm{~mm}$ mesh-size tulle covering $1 \times 1 \mathrm{~m}$ surface at the ground level. To estimate herbivore damage we measured for every plant within the cage the Apical Dominance Index $(\mathrm{ADI})=$ number of ramifications / stem height. This index reflects the dominance of the apical meristem compared to lateral meristems and the resulting plant architecture (Pérez-Harguindeguy et al. 2013). The ADI of each excluded plant was compared with the ADI of one non-excluded plant randomly selected within a $2 \mathrm{~m}$ radius from the excluded plant to compute the $\triangle \mathrm{ADI}=\mathrm{ADI}_{\text {excluded }}-\mathrm{ADI}_{\text {non-excluded }}$, reflecting the estimated herbivory for each field. All plants were selected at least $5 \mathrm{~m}$ away from the field limits to avoid any border effect. The exclusion of phytophagous insects from plant germination until flowering (four to five months) represented a major challenge because the cages were vulnerable to several adverse conditions (strong winds, destruction by wildlife...). Nevertheless, this exclusion time is long compared with most studies in the literature that generally focus on short generation-time insects (e.g. aphids; see list in Karp et al. 2018). Even though the sample size may seem low, it is similar with other studies on this topic (e.g. ChaplinKramer et al. 2011; Thies et al. 2011). Temperatures outside and inside the cage were recorded during one week which resulted in a mean temperature inside the cage $1.12{ }^{\circ} \mathrm{C}$ higher than outside. This difference in temperature is lower than the natural thermal variability measured within one field (Faye et al. 2016).

Within the same fields, we randomly selected two plants not included in the herbivore exclusion experiment, for which two inflorescences were excluded from pollinators. The cage was made with a tulle with mesh size of $0.36 \mathrm{~mm}$, with a height of $50 \mathrm{~cm}$ and a width of $30 \mathrm{~cm}$. The pollinators were excluded from pre-flowering to harvest. To estimate pollination we counted the number of developed and aborted ovules per pod and computed a Developed Seed Index (DSI) $=$ number of developed ovules/(number of developed ovules + number of aborted ovules). The DSI of non-pollinated inflorescence were compared with the opposite inflorescence from the same plant where pollinators were allowed, in order to compute the $\triangle \mathrm{DSI}=\mathrm{DSI}_{\text {pollinated }}$ - DSI $I_{\text {unpollinated }}$.

Field yield was estimated by harvesting all the seeds from three randomly selected plant groups covering $1 \mathrm{~m}^{2}$ surface (plants emerging from the same seed hole). The seeds were dried for $48 \mathrm{~h}$ at $80{ }^{\circ} \mathrm{C}$ and their dry biomass was weighted (precision of $0.1 \mathrm{~g}$ ) (PérezHarguindeguy et al. 2013). We computed the yield (kg/ ha) = plant group dry biomass $(\mathrm{kg}) \times 1\left(\mathrm{~m}^{2}\right) \times 10000$ $\left(\mathrm{m}^{2}\right)$.

\section{Statistical analyses}

From the 35 initial fields selected, 9 were left with a complete set of data at the end of the experiment, reflecting the difficulties associated with participatory research. Indeed, 18 farmers lost interest in the participatory monitoring of insects. Exclusion experiments were carried out within the 17 fields left but in 6 fields the cages were damaged or disappeared. We therefore flew the drone in the 11 fields where the cages were not damaged and where insects were still monitored by the farmers. Finally, pesticide use information was missing for 2 fields where farmers were unreachable.

We constructed a path analysis to explore the relationships of landscape and pesticide use on herbivory, pollination and ultimately yield (Fig. 1). Path analysis is a particular case of structural equation model with inner model only, that estimates direct, indirect, and total effects of explanatory variables on dependent variables to describe correlations among them (Sanchez 2013). Path analysis is used to explore theoretically designed hypothesis. In path analysis variables are either exogenous (e.g. drivers) or endogenous (e.g. ecosystem service indicators) depending on hypothesized pathways. The exogenous variables included were the proportion of semi-natural cover and the number of pesticide applications while the endogenous variables were the field yield, the abundance of apex borer, the abundance of pollinators, the ADI and the DSI. R-squared values for endogenous variables show the amount of variation explained. The path coefficients depict the correlation between two variables. We assessed the differences in mean ADI and DSI between excluded and non-excluded plants using two Generalized Linear Mixed Models (GLMM) with field as random effect. For ADI, we used a Gamma error distribution to account for the long tail distribution. For DSI we used a Binomial error distribution with a logit link function to account for the proportional nature of this index, and we also used the total number of seeds to weight the GLMM.

Statistical analyses were performed using $\mathrm{R}$ v3.5.1 ( $\mathrm{R}$ Core Team 2018), the path analysis was performed using the plspm R package (Sanchez 2013) and the GLMM using glmer function from the lme4 package.

\section{Results}

Our results revealed only two significant relationships from our hypothesized path analysis (Fig. 3). First, we found significant negative effect $(\mathrm{p}=0.021$; pathcoefficient $=-0.892$ ) of the number of pesticide applications on pollinator abundance (Fig. 3), suggesting a high pollinator mortality due to tested pesticide use. Second, a positive significant effect $(\mathrm{p}=0.014$; pathcoefficient $=0.776$; Fig. 3) arose between apex borer 


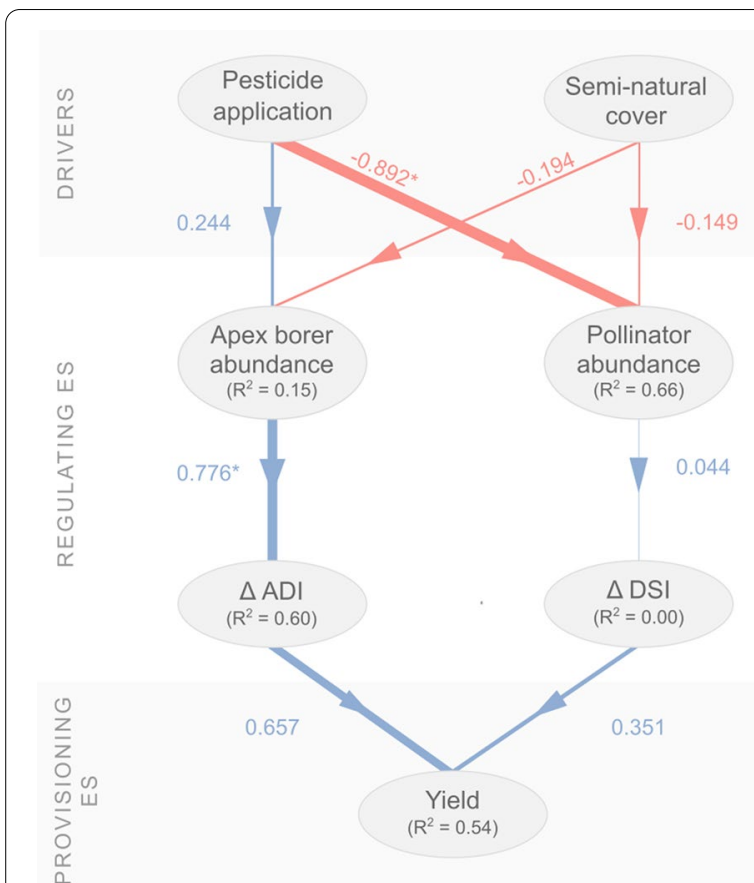

Fig. 3 Observed relationships between ecosystem services and their drivers based on experimentally gathered data. R-squared values for endogenous variables show the amount of variation explained. Path weights are represented by numbers next to the arrows and the arrows' widths. Significant relationships are marked with *. ADI Apical Dominance Index, DSI Developed Seed Index, ES Ecosystem Service

abundance and ADI, reflecting the capacity of apex borer to modify plant architecture. This hypothesis was also supported by the significantly lower herbivory for plants excluded from insects $(p<0.001$; Fig. 4a,
Additional file 1: Fig. S3, Table S4) with a mean ADI $25.7 \%$ higher compared to excluded plants. We also found a significant effect of pollinator exclusion on pollination ( $p=0.017$, Fig. 4b, Additional file 1:Fig. S4, Table S5), with non-excluded flowers exhibiting a mean DSI higher by $10.5 \%$ compared to excluded flowers. All the other relationships depicted in the path analysis showed non-significant effects (Fig. 3).

\section{Discussion}

Natural habitat conservation at the landscape scale has been proposed as another pest management strategy that can be integrated with pesticide use, with synergistic benefits for pollination (Ricketts et al. 2008; Gurr et al. 2017). Therefore, sprayed crops and semi-natural areas are embedded within the same landscape, interacting together. Our study documents a case of the combined effect of these two drivers in a smallholder farming system in the Ecuadorian Andes, with small size fields ( $<1-2$ ha) and diversified crops.

From our initial sample of 30 farms, we were able to obtain complete data for only 9 farms due to issues during our participatory monitoring of insects, and to the long time-scale of the exclusion experiments (during the whole crop cycle, see also Dangles et al. 2010 for a discussion on benefits and drawbacks of crop pest participatory monitoring). Therefore, most of our nonsignificant results could be due to the low sample size we ended with. We nevertheless discuss our significant results and explore alternative hypothesis for non-significant effects with potential biological mechanisms at work.

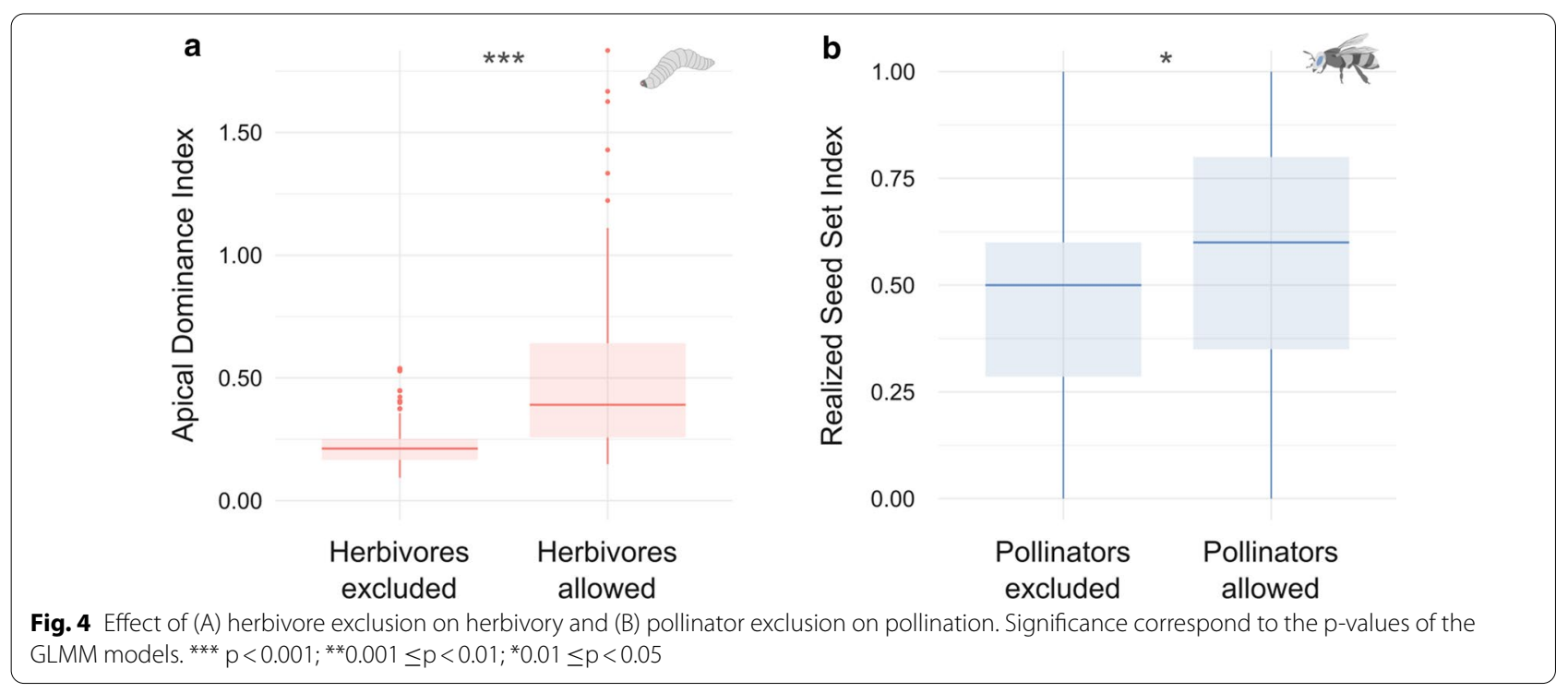




\section{Pesticide effect on pollinators and pests}

Our study showed a significant negative effect of pesticide applications on pollinator abundance (Fig. 3). While similar results have been reported in intensified cropping systems (e.g. Johnson et al. 2010; de Oliveira et al. 2019), there are fewer support of this process in smallholder farms where application occurs at a reduced scale, with weaker farmer's knowledge of the products and their hazards (e.g. Mengistie et al. 2017). Pollinators play a key role because $35 \%$ of the global food production is dependent on animal pollination (Klein et al. 2007). However major crop production in the Andes may be more resistant to pollinator disappearance than other regions because some of the major crops grown here are not dependent on animal pollination (e.g. maize, potato, quinoa; Appendix 1 and 2 in Klein et al. 2007). While pesticide use significantly decreased pollinator abundance, no significant effect of pesticide could be found on pest abundance. We hypothesize that this result could be linked with the ecology of the pest as only a small amount of pesticide can reach it within its protective refuge inside the stem.

\section{Effects of landscape composition on pollinators and pests}

While pesticide had a significant effect on pollinators, our results showed only non-significant effects of the proportion of semi-natural cover surrounding the field on abundance of both pests and pollinators (Fig. 3). The underlying biological mechanism behind our initial hypothesis was that more floral resources (e.g., shelter and nectar) were present in semi-natural habitat than cultivated crops, which would be beneficial to both natural enemies (Gurr et al. 2017) and pollinators (Ricketts et al. 2008). However, this hypothesis was not supported by our results. This finding could be related with the small field size and the crop heterogeneity within the landscape compared to temperate areas. Indeed, Sirami et al. (2019) showed that reducing field size and increasing crop diversity lead to similar benefits for biodiversity and related ecosystem services than increasing seminatural habitat cover. Moreover, the proportion of seminatural habitat in our landscapes were high (20-60\%) compared to ranges commonly found in the literature (Sirami et al. 2019). Thus, we suggest that these farming systems may not benefit from an additional increase in semi-natural habitat because the current traditionnal farming practices already foster a relatively high heterogeneity of crop and conservation of semi natural habitats within the landscape. Furthermore, in the tropical region, crop spatial heterogeneity is even higher because of an additional phenological heterogeneity (i.e. crops at different lifecycle stages) allowed by the absence of seasonality.
We believe that these aspects should be further explored in smallholder farm systems to verify this hypothesis.

\section{Effects of pollination on Andean lupine}

Our results also showed that flower visitation by insects increased the mean seed set by $10.5 \%$ (Fig. $4 \mathrm{~b}$ ). This is consistent with what has been found for other species of lupine, which display a combination of allogamous (through cross-pollination) and autogamous reproductions (Cowling et al. 1998). However, the cross-pollination rate has been shown to be highly variable among species and individuals, depending on genetic and environmental factors such as plant variety and distance to conspecifics (Cowling et al. 1998). For Lupinus mutabilis, Cowling et al. (1998) reported a cross-pollination rate of 4 to $11 \%$, while experiments conducted by Caligari et al. (2000) found an outcrossing rate reaching up to $58.8 \%$. Our results add up to the literature, suggesting that allogamous reproduction in L. mutabilis has a significant impact on increasing fruit production. We also provide the first evidence that seed production of the variety "450-Andino" of Andean lupine, the dominant variety used as a crop in Ecuador, is increased by pollination. Although pollination increased seed production, the abundance of pollinators had almost no effect on pollination (Fig. 3). This surprising result could be due to the fact that Apidae family may not be the main pollinator of Andean's lupine in our study area compared to study carried out in Peru (Ochoa-Zavala et al. 2016). Another explanation could be linked with the "flower tripping" pollination mechanism occurring in other lupine species (Williams 1987). Flower tripping is a self-pollination triggered by the movements (landing, take-off) of large insect within the flower, resulting in a very generalist pollination mechanism. If this mechanism takes place in Andean lupine, it could explain why the abundance of Apidae only had no effect on fruit production, because any large generalist insect could pollinate the flowers inadvertently. It is yet unknown whether this mechanism takes place in Andean lupine reproduction, and additional studies should focus on this aspect to shed light on this understudied part of its ecology, for example by manually simulating flower tripping events.

\section{Effect of pest on Andean lupine architecture and yied}

A positive significant effect was observed between apex borer abundance and the apical dominance index, indicating that this pest is able to transform Andean lupine's architecture (Fig. 3). Indeed, the fly's larvae feed on the internal tissues of the plant and frequently damages apical meristems. In response, the Andean lupine plant 
stimulates its lateral meristems growth, resulting in a significant change in plant architecture to compensate the loss induced by the pest (Fig. 4a). When the compensation exceeds the loss, a mechanism called overcompensation takes place, leading to a higher growth than if the plant was left undamaged. Overcompensation can be either reproductive (increased fruit production) or vegetative (increased vegetative growth). Even though reproductive overcompensation seems widespread for species in the Fabaceae family (Garcia and Eubanks 2018), our results do not support this hypothesis as herbivory did not significantly increase yield. Nevertheless, a case of reproductive overcompensation for $L$. mutabilis was previously reported in the literature (Porter 1982), where overcompensation was induced in an opposite manner (cutting lateral branches increased pod set in apical flowers). Overall, our study shows that the apex borer does not significantly increase nor decrease Andean lupine's yield, which suggests that the plant is able to compensate for the damage taken. Therefore, even though the apex borer's damage is very conspicuous due to the plant's architecture modifications, our results suggest that this species may not be as detrimental to crop production as farmers currently perceive.

\section{Limitations of the study}

Several factors that we did not account for, such as tillage, crop rotation, use of fertilizers or timing and modes of action of pesticide could influence the biology of pests and the vulnerability of lupine to pests, and should therefore be further studied. Additionally, our analysis would have beneficiated from a multiyear experiment because climatic conditions also influence the biology of pests and pollinators. Finally, we believe that more knowledge needs to be gathered about the biology of pests and pollinators associated with Andean lupine because knowing the functional relationships between habitats and insects would help to define functionally meaningful semi-natural habitat to be measured within the landscape.

\section{Conclusions}

This study shows that pesticide use had an overall greater impact on the entomofauna associated with Andean lupine fields than the presence of semi natural habitats nearby. We propose that further studies should explore the role of crop spatial and temporal diversities within the landscape to explain this absence of effect, as the Ecuadorian Andes are very diverse landscapes, both spatially and temporally. Our results also provide information about Andean lupine reproduction and overcompensation mechanisms that could be of interest for local farmers and researchers of this understudied crop.

\section{Supplementary Information}

The online version contains supplementary material available at https://doi. org/10.1186/s43170-021-00027-w.

Additional file 1. Additional tables and figures.

\section{Acknowledgements}

The authors are grateful to all the farmers involved in the insect monitoring, and for their time and fruitful interactions during the workshops. We thank Pablo Cozzaglio for his help with flying the drone and obtain the images. We are grateful to Claire Nicklin, Aurélie Coulon, Paolo Campo, and four anonymous reviewers for their helpful comments on a previous version of the manuscript. We also thank Claire Capdevielle-Dulac for her help with DNA barcoding of the entomofauna associated with Andean lupine. We finally thank Émile Faye for his advices for landscape orthophoto computation and the Coro family for their help with the manufacturing of exclusion cages.

\section{Authors' contributions}

QS and OD designed research; QS and DM performed research and collected data; QS and OD analysed data; QS led the writing with contributions from

DM and OD. All authors read and approved the final manuscript.

\section{Funding}

This work is part of the project "Adaptive and integrated management of lupin pests in social-ecological agroscapes in the Andes" (LEGUMIP) conducted within the Crop Collaborative Research Program funded by the McKnight Foundation.

Availability of data and materials

All data necessary to compute the figures are available as supplementary material.

Ethics approval and consent to participate

Not applicable.

\section{Consent for publication}

Not applicable.

\section{Competing interests}

Authors declare no conflict of interests.

\section{Author details}

${ }_{1}^{1}$ Muséum National d'Histoire Naturelle, Sorbonne Universités, 57 rue Cuvier, 75005 Paris, France. ${ }^{2}$ Institut de Recherche pour le Développement, Centre d'Ecologie Fonctionnelle et Evolutive, UMR 5175, CNRS, Université de Montpellier, Université Paul Valéry Montpellier, EPHE, IRD, Montpellier, France. ${ }^{3}$ Faculty of Exact and Natural Sciences, Pontifical Catholic University of Ecuador, Quito, Ecuador.

Received: 9 October 2020 Accepted: 3 February 2021

Published online: 17 February 2021

\section{References}

Bates HW. XXXII. Contributions to an insect fauna of the Amazon Valley. Lepidoptera: Heliconidae. Trans Linn Soc Lond. 1862:23:495-566.

Bianchi FJJA, Booij CJH, Tscharntke T. Sustainable pest regulation in agricultural landscapes: a review on landscape composition, biodiversity and natural pest control. Proc R Soc B Biol Sci. 2006;273:1715-27.

Blacquière T, Smagghe G, van Gestel CAM, Mommaerts V. Neonicotinoids in bees: a review on concentrations, side-effects and risk assessment. Ecotoxicology. 2012:21:973-92.

Caicedo V and Peralta I. 2000. Zonificación potencial, sistemas de producción y procesamiento artesanal del chocho (Lupinus mutabilis Sweet) en Ecuador.

Caligari PDS, Römer P, Rahim MA, et al. The Potential of Lupinus mutabilis as a crop. In: Knight R, editor., et al., Linking Research and Marketing 
Opportunities for Pulses in the 21st Century. Dordrecht: Springer; 2000. p. 569-73.

Chaplin-Kramer R, O'Rourke ME, Blitzer EJ, Kremen C. A meta-analysis of crop pest and natural enemy response to landscape complexity: Pest and natural enemy response to landscape complexity. Ecol Lett. 2011;14:922-32.

Cowling WA, Buirchell BJ, Tapia ME. Lupin: Lupinus L. Rome: IPGRI; 1998.

Dangles O, Carpio FC, Villares M, et al. Community-based participatory research helps farmers and scientists to manage invasive pests in the ecuadorian andes. Ambio. 2010:39:325-35.

de Oliveira AC, Junqueira CN, Augusto SC. Pesticides affect pollinator abundance and productivity of sunflower ( Helianthus annuus L.). J Apic Res. 2019;58:2-8.

Desneux N, Decourtye A, Delpuech J-M. The sublethal effects of pesticides on beneficial arthropods. Annu Rev Entomol. 2007;52:81-106.

Dutcher JD. A review of resurgence and replacement causing pest outbreaks in IPM. In: Ciancio A, Mukerji KG, editors. General concepts in integrated pest and disease management. Dordrecht: Springer; 2007. p. 27-43.

Faye E, Rebaudo F, Yánez-Cajo D, et al. A toolbox for studying thermal heterogeneity across spatial scales: from unmanned aerial vehicle imagery to landscape metrics (A Tatem, Ed). Methods Ecol Evol. 2016;7:437-46.

Gagic V, Kleijn D, Báldi A, et al. Combined effects of agrochemicals and ecosystem services on crop yield across Europe (C Scherber, Ed). Ecol Lett. 2017;20:1427-36

Gagic V, Hulthen AD, Marcora A, et al. Biocontrol in insecticide sprayed crops does not benefit from semi-natural habitats and recovers slowly after spraying (I Kaplan, Ed). J Appl Ecol. 2019. https://doi.org/10.1111/13652664.13452.

Garcia LC, Eubanks MD. Overcompensation for insect herbivory: a review and meta-analysis of the evidence. Ecology. 2018. https://doi.org/10.1002/ ecy. 2585 .

Gill HK and Garg H. 2014. Pesticides: environmental impacts and management strategies. In: Pesticides-toxic aspects. IntechOpen.

Gill RJ, Ramos-Rodriguez O, Raine NE. Combined pesticide exposure severely affects individual- and colony-level traits in bees. Nature. 2012;491:105-8.

Gurr GM, Wratten SD, Landis DA, You M. Habitat management to suppress pest populations: progress and prospects. Annu Rev Entomol. 2017;62:91-109.

Haan NL, Zhang Y, Landis DA. Predicting landscape configuration effects on agricultural pest suppression. Trends Ecol Evol. 2020;35:175-86.

Hayes MM, Miller SN, Murphy MA. High-resolution landcover classification using Random Forest. Remote Sens Lett. 2014;5:112-21.

Johnson RM, Ellis MD, Mullin CA, Frazier M. Pesticides and honey bee toxicity USA. Apidologie. 2010;41:312-31.

Karp DS, Chaplin-Kramer R, Meehan TD, et al. Crop pests and predators exhibit inconsistent responses to surrounding landscape composition. Proc Natl Acad Sci. 2018;115:E7863-70.

Klein A-M, Vaissière BE, Cane JH, et al. Importance of pollinators in changing landscapes for world crops. Proc R Soc B Biol Sci. 2007;274:303-13.

Landis DA, Wratten SD, Gurr GM. Habitat management to conserve natural enemies of arthropod pests in agriculture. Annu Rev Entomol. 2000;45:175-201

Mengistie BT, Mol APJ, Oosterveer P. Pesticide use practices among smallholder vegetable farmers in Ethiopian Central Rift Valley. Environ Dev Sustain. 2017:19:301-24

Mina D, Struelens Q, Carpio C, et al. Lupin pest management in the ecuadorian Andes: current knowledge and perspectives. Outlooks Pest Manag. 2017;28:250-6.
Morgulis A, Coulouris G, Raytselis Y, et al. Database indexing for production MegaBLAST searches. Bioinformatics. 2008;24:1757-64.

Nicklin C, Rivera M, Nelson R. Realizing the potential of an Andean legume: roles of market-led and research-led innovations. Int J Agric Sustain. 2006:4:61-78

Ochoa-Zavala M, Suárez-Montes P, Chávez-Pesqueira M, et al. 2016. Diferencias en morfología y visitantes florales entre Lupinus mutabilis y Lupinus aff. ballianus en la microcuenca de Warmiragra, Perú. 9.

Pérez-Harguindeguy N, Díaz S, Garnier E, et al. New handbook for standardised measurement of plant functional traits worldwide. Aust J Bot. 2013;61:167.

Porter N. Interaction between lateral branch growth and pod set in primary inflorescences of lupin. Aust J Agric Res. 1982;33:957.

Poveda K, Martínez E, Kersch-Becker MF, et al. Landscape simplification and altitude affect biodiversity, herbivory and Andean potato yield: Landscape affects potato pests and yield. J Appl Ecol. 2012;49:513-22.

R Core Team. R: A Language and Environment for Statistical Computing. Vienna: R Foundation for Statistical Computing; 2018.

Ricci B, Franck P, Toubon J-F, et al. The influence of landscape on insect pest dynamics: a case study in southeastern France. Landsc Ecol. 2009;24:337-49.

Ricci B, Lavigne C, Alignier A, et al. Local pesticide use intensity conditions landscape effects on biological pest control. Proc R Soc B Biol Sci. 2019:286:20182898.

Ricketts TH, Regetz J, Steffan-Dewenter I, et al. Landscape effects on crop pollination services: are there general patterns? Ecol Lett. 2008;1 1:499-515.

Roubik DW, editor. Pollination of cultivated plants in the tropics. Rome: Food and Agriculture Organization of the United Nations; 1995.

Samnegård U, Hambäck PA, Lemessa D, et al. A heterogeneous landscape does not guarantee high crop pollination. Proc R Soc B Biol Sci. 2016:283:20161472.

Sanchez G. PLS path modeling with R. Trowchez Editions. Berkeley; 2013. http://www.gastonsanchez.com/PLS_Path_Modeling_with_R.pdf.

Schreinemachers P, Tipraqsa P. Agricultural pesticides and land use intensification in high, middle and low income countries. Food Policy. 2012:37:616-26.

Shackelford G, Steward PR, Benton TG, et al. Comparison of pollinators and natural enemies: a meta-analysis of landscape and local effects on abundance and richness in crops: Comparison of pollinators and natural enemies. Biol Rev. 2013;88:1002-21.

Sirami C, Gross N, Baillod AB, et al. Increasing crop heterogeneity enhances multitrophic diversity across agricultural regions. Proc Natl Acad Sci. 2019;116:16442-7.

Thies C, Haenke S, Scherber C, et al. The relationship between agricultural intensification and biological control: experimental tests across Europe. Ecol Appl. 2011;21:2187-96.

Veres A, Petit S, Conord C, Lavigne C. Does landscape composition affect pest abundance and their control by natural enemies? A review. Agric Ecosyst Environ. 2013:166:110-7.

Williams IH. The pollination of lupins. Bee World. 1987;68:10-6.

\section{Publisher's Note}

Springer Nature remains neutral with regard to jurisdictional claims in published maps and institutional affiliations.

Ready to submit your research? Choose BMC and benefit from:

- fast, convenient online submission

- thorough peer review by experienced researchers in your field

- rapid publication on acceptance

- support for research data, including large and complex data types

- gold Open Access which fosters wider collaboration and increased citations

- maximum visibility for your research: over 100M website views per year

At BMC, research is always in progress.

Learn more biomedcentral.com/submissions 